TITLE:

$<$ Note $>$ Why Don't the

Chimpanzees of M Group at Mahale Fish for Termites?

$\operatorname{AUTHOR}(S)$ :

Uehara, Shigeo

CITATION:

Uehara, Shigeo. <Note> Why Don't the Chimpanzees of M Group at Mahale Fish for Termites?. Pan Africa News 1999, 6(2): 22-24

ISSUE DATE:

1999-12

URL:

http://hdl.handle.net/2433/143376

RIGHT:

Copyright (C) Pan Africa News. 


\title{
<NOTE>
}

\section{Why Don't the Chimpanzees of $M$ Group at Mahale Fish for Termites?}

\author{
Shigeo Uehara \\ (Primate Research Institute, Kyoto University)
}

In the Mahale Moutains National Park, Tanzania, chimpanzees are known to fish for two species of termites, Macrotermes ?herus and Pseudacanthotermes spiniger (1). The chimpanzees of B Group have been confirmed to fish for $M$. ?herus (2), while the chimpanzees of $\mathrm{K}$ Group (no more existing) were observed to fish for P. spiniger in 1977 and 1978 (3). In contrast, we have never observed the chimpanzees of $M$ Group to fish for termites at all, although two immigrant individuals from $\mathrm{K}$ Group (GW and LL) were seen to do so in 1981 (4). GW (a female now very old) is still alive, but she has never been witnessed again to practice the same activity since then.

According to the detailed study by Collins and McGrew (5), termite fauna àt Mahale clearly showed local differences. In the range of B Group which is the northernmost study population at Mahale, mounds of Macrotermes were not rare. In the range of neighboring $\mathrm{K}$ Group, mounds of Macrotermes did not exist while those of Pseudacanthotermes were common. Such differences in termite fauna may be caused at least partly by the conspicuous local differences in annual rainfall between the ranges of two groups (6). Regrettably, no relevant data have been reported from the exclusive range of $M$ Group (5), the southernmost population of the three study groups.

GW might have failed to transmit the "termite-fishing culture" to $M$ Group. The former range of $\mathrm{K}$ Group is now commonly utilized by $M$ Group after the expansion of its range to the north, although availability alone does not always explain the choice of termite prey by chimpanzees (7). However, this speculation remains still tentative at the moment. 


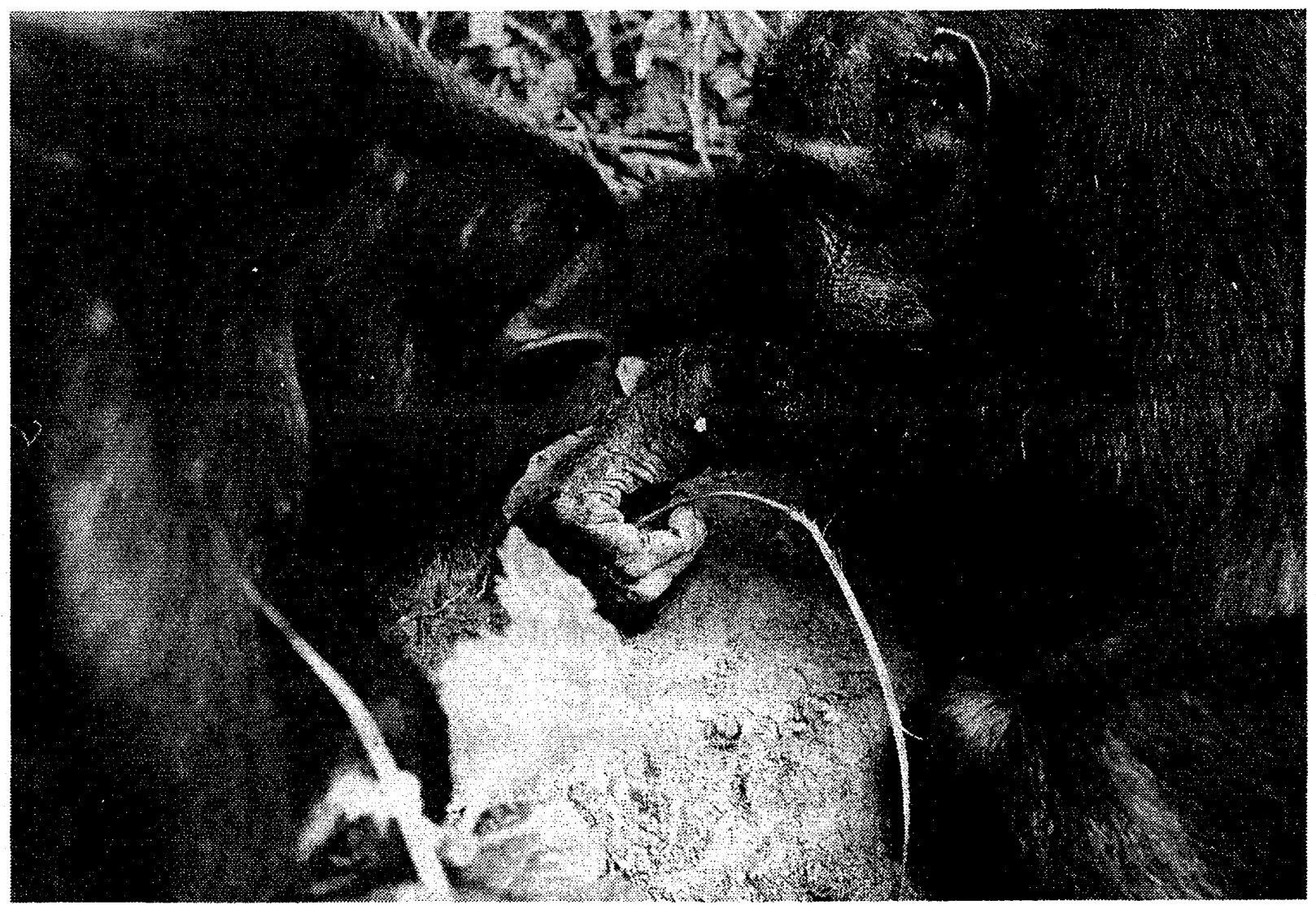

\section{GW (left) watches WT's (right) termite-fishing, probably anticipating to take over the fishing site (K Group: November 24, 1977).}

Besides chimpanzees, there are very many animals which prey on terimites. Some extreme cases such as invasions by Dorylus ants bring the sudden "death" of Macrotermes mounds (8), although it is unclear if the same phenomena occur for the mounds of Pseudacanthotermes. Moreover, competition for the same mounds seems to exist among different species of termites $(5,8)$.

Diachronic changes in distribution and abundance of mammals clearly affect the prey profile of hunting by the chimpanzees of $M$ Group (9). With respect to the termite fauna at Mahale, continuous monitoring to follow changes in distribution and density is needed as well in order to understand the complicated relationship between chimpanzees and termites.

\section{References}

(1) Nishida, T. \& Uehara, S., 1980. Chimpanzees, tools, and termites: Another example from
Tanzania. Curr. Anthropol., 21: 671-672.

(2) McGrew, W. C. \& Collins, D. A, 1985. Tool use by wild chimpanzees (Pan troglodytes) to obtain termites (Macrotermes herus) in the Mahale Mountains, Tanzania. Amer. $J$. Primatol., 9: 47-62.

(3) Uehara, S., 1982. Seasonal changes in the techniques employed by wild chimpanzees in the Mahale Mountains, Tanzania, to feed on termites (Pseudacanthotermes spiniger). Folia Primatol., 37: 44-76.

(4) Takahata, Y., 1982. Termite-fishing observed in the $\mathbf{M}$ group chimpanzees. Mahale Mountains Chimpanzee Research Project, Ecological Report No. 18.

(5) Collins, D. A. \& McGrew. W. C.. 1987. Termite fauna related to differences in tool-use between groups of chimpanzees (Pan troglodytes). Primates, 28: 457-471.

(6) Takasaki, H., Nishida. T., Uehara, S., Norikoshi, K., Kawanaka, K., Takahata, Y., Hiraiwa-Hasegawa, M., Hasegawa, T., 
Hayaki, H., Masui, K. \& Huffman, M. A. 1990. Summary of meteorological data at Mahale research camps, 1973-1988. In: T. Nishida (ed.), The Chimpanzees of the Mahale Mountains: Sexual and Life History Strategies, University of Tokyo Press; Tokyo, pp. 291-300.

(7) Collins, D. A. \& McGrew, W. C., 1985. Chimpanzees' (Pan troglodytes) choice of prey among termites (Macrotermitinae) in Western
Tanzania. Primates, 26: 375-389.

(8) Howse, P. E., 1970. Termites: A Study in Social Behaviour, Hutchinson, London.

(9) Uehara, S. \& Thobe, H., 1998. Distribution and abundance of diurnal mammals, especially monkeys, at Kasoje, Mahale Mountains, Tanzania. Anthropol Sci., 106: 349-369. 